\title{
Parallel worlds: an ethnography of care in an Afghan maternity hospital
}

\section{Article}

Accepted Version

Creative Commons: Attribution-Noncommercial-No Derivative Works 4.0

Arnold, R., van Teijlingen, E., Ryan, K. and Holloway, I. (2018) Parallel worlds: an ethnography of care in an Afghan maternity hospital. Social Science \& Medicine, 216. pp. 33-40. ISSN 0277-9536 doi:

https://doi.org/10.1016/j.socscimed.2018.09.010 Available at https://centaur.reading.ac.uk/79317/

It is advisable to refer to the publisher's version if you intend to cite from the work. See Guidance on citing.

To link to this article DOI: http://dx.doi.org/10.1016/j.socscimed.2018.09.010

Publisher: Elsevier

All outputs in CentAUR are protected by Intellectual Property Rights law, including copyright law. Copyright and IPR is retained by the creators or other copyright holders. Terms and conditions for use of this material are defined in the End User Agreement.

\section{www.reading.ac.uk/centaur}

\section{CentAUR}

Central Archive at the University of Reading 
Reading's research outputs online 
Parallel worlds: an ethnography of care in an Afghan maternity hospital

\section{Abstract}

3 Aspirations of quality, equitable and respectful care for all women in childbirth have,

4 so far, been unrealised. Sub-optimal care remains the norm in many settings despite

5 decades of substantial investment, the introduction of evidence-based policies,

6 procedures and training programmes. Improving the standard of institutional care for

7 childbearing women in Afghanistan is an example.

8 This ethnography of a large public Afghan maternity hospital explored the

9 experiences, motivations and constraints of healthcare providers. The aim was to

10 identify barriers and facilitators in the delivery of care. Participant observation, semi-

11 structured interviews, and focus group discussions were used to gather diverse

12 perspectives on childbirth and care between 2010 and 2012. The influences of the

13 sociocultural setting and political economy on facility-based care are discussed in this

14 paper.

15 Under the surface of this maternity hospital, social norms were in conflict with the 16 principles of biomedicine. Contested areas included the control of knowledge, equity

17 and the primary goal of work. The institutional culture was further complicated by

18 pressure from powerful elites. These unseen values and pressures explain much of

19 the disconnection between policy and implementation, education and the everyday

20 behaviours of healthcare providers. Improving the quality of care and equity in

21 Afghan public maternity hospitals will require political will from all stakeholders to

22 acknowledge these issues and find culturally attuned ways to address them.

23 Furthermore, the notion of competing world-views on healthcare has relevance

24 beyond Afghanistan. 


\section{Research highlights}

- Afghan biomedical practice is being shaped by history, society and politics

- Connections, status or financial gifts were required to access quality care

- Professional knowledge and clinical skills were generally guarded not shared

- Social expectations and pressures were stronger than notions of equity

- Political elites had power and influence over healthcare providers

Keywords

Afghanistan; critical ethnography; sociocultural values; respectful care; equity; quality of care; political economy; patronage

\section{INTRODUCTION}

Despite three decades of global commitment, activism and investment in maternal health, women are still dying needlessly in low, middle and high-income countries (Shaw et al., 2016; Victora et al., 2016). As governments, international donors and healthcare implementers focus on the sustainable development goals many challenges remain such as achieving good standards of care for childbearing women in public health facilities (Koblinsky et al., 2016). Ensuring that the poorest and most

vulnerable women in society access the services they need and are treated with kindness is currently little more than an aspiration in most settings (Barros et al., 2012; Graham et al., 2016; Mumtaz et al., 2014).

Evidence-based policies and procedures now generally form the basis for healthcare provider education and clinical protocols globally (Renfrew et al., 2014). The day-to- 
day practice of care workers, however, is mediated by more innate values and priorities (Andersen, 2004; Jaffré, 2012). Understanding the diverse and complex social worlds that define healthcare providers in each unique setting is a vital step in understanding some of the most intractable issues in $21^{\text {st }}$ century healthcare (PanterBrick \& Eggerman, 2018; Pitchforth et al., 2010).

In Kabul, state sponsored public health provision did not commence until the early $20^{\text {th }}$ Century when Turkish and Indian doctors were employed to set up a hospital and clinic. Health clinics for women did not commence until the 1940's although a French couple opened an unofficial midwifery school in the 1930's. A Western-styled health system including a medical university grew throughout the $20^{\text {th }}$ Century, although it faced opposition and functioned alongside traditional beliefs and practices (Gregorian, 1969; Hunte, 1980). The fall of the Taliban regime in 2001 brought new opportunities and impetus to rebuild and strengthen the health system devastated by decades of conflict.

Since then, the Afghan Ministry of Public Health (MoPH) and international community have made the reduction of maternal and newborn/child mortality a priority (Jhpiego, 2018; Ministry of Public Health, 2005, 2012). Addressing the dearth of female healthcare providers has been a key strategy. Kabul medical university resumed the education of female doctors and new national midwifery curricula were developed incorporating competency-based learning approaches and a job description based on the International Midwifery Confederation educational framework (ICM, 2002). The new standardised midwifery education programme replaced a hotchpotch of short to medium term courses run by international agencies throughout the country. Over 4,600 midwives were trained between 2004 and 2014 (Currie et al., 2007; United Nations Population Fund, 2014). Although the training is highly valued, translating the potential of these professional women and their skills into quality care for all Afghan 
75 women and their unborn babies has been an elusive goal (Guidotti et al., 2009;

76 Jhpiego, 2013; Kim et al., 2012; Rahmani \& Brekke, 2013).

77 Recent reviews conclude that Afghanistan has made progress in improving maternal

78 and child health, especially given the low starting point, poverty and ongoing

79 insecurity (Akseer et al., 2016; Bartlett et al., 2017). Amongst the challenges noted

80 are the unacceptably high maternal mortality ratio and poor quality of public hospitals

81 (Central Statistics Organisation et al., 2016; Ministry of Public Health, 2017; Tappis et 82 al., 2016).

83 This study explored the culture of care and the perspectives of Afghan doctors,

84 midwives and care assistants on healthcare delivery in one maternity hospital. The

85 aim was to understand the disconnection between good standard educational

86 programmes and the low-level care that women in facility-based childbirth often

87 received.

$88 \quad$ Methods

89 This study used a critical ethnographic approach to illuminate the values and

90 meanings underlying staff behaviours as well as the multiple realities and power

91 differences (Hammersley \& Atkinson, 2007; Thomas, 1993). RA, a British nurse-

92 midwife researcher with broad cross-cultural experience and eight years in

93 Afghanistan conducted the research. She was familiar with the hospital having

94 overseen student midwives' clinical placements there some years previously but

95 wanted to understand care, and challenges with standards of care from the

96 perspective of the healthcare providers. The research was conducted from a

97 constructionist philosophical stance, "an epistemological approach which assumes

98 that there are no stable, pre-existing phenomena... but seeks to address questions of 
99

100

101

102

103

104

105

106

107

108

109

how those phenomena are created through social processes" (Green \& Thorogood, 2018, p.385).

A busy public Kabul maternity hospital was chosen for this study with permission from the MoPH and the hospital director. The hospital received mainly poor women who could not afford private hospitals. Officially public hospitals are free, however, unofficially out of pocket expenditure is the norm (Bartlett et al., 2017). Data collection including interviews, focus group discussions (FGD) and participant observation occurred during several field trips organised between 2010 and 2012.

Since RA had only basic Dari a young Afghan woman was recruited as an interpreter, trained and orientated to the study (Temple \& Young, 2004). Information sheets in Dari and Pashtu were placed in prominent areas throughout the hospital prior to data collection. The logistics of observation were discussed with senior medical and midwifery staff, and RA, her interpreter and the study were introduced at several staff meetings.

Participant observation included all areas of the hospital during both day and night to ensure data sufficiency. During observation field notes were taken to capture the setting, staff practices and interactions (Wallace, 2005). These were typed up and expanded as soon as possible afterwards. Informal talks with individuals and groups of staff members helped to build a rapport and provided initial insights into the pertinent issues and tensions (Brewer, 2000). Semi-structured interviews with 23 staff members then explored topics in more depth (Sherman Heyl, 2001), using a mixture of opportunistic and purposive sampling. Interviews were conducted with senior doctors and midwives, resident doctors, newly qualified midwives and care assistants to ensure that a broad variation of views was represented (Sharkey \& Larsen, 2005). Questions included: 'Tell me about care in this hospital'; 'What part of 
124 your work do you enjoy the most?'; and 'What are the most difficult things about

125 working in this hospital'? Most interviews were semi-structured, however, some staff

126 did not need prompting to share their experiences, ideas or frustrations. It was

127 important to calibrate observations of care with the wishes of Afghan women

128 regarding childbirth rather than Western notions of what is desirable. FGDs (van

129 Teijlingen \& Pitchforth, 2006) were, therefore, held with two groups of women from

130 different socioeconomic backgrounds and communities to discover their experiences

131 and wishes regarding childbirth. The first FGD consisted of six female members of

132 one extended family; the second FGD consisted of ten unrelated women aged 23-56

133 who were members of a self-help group in a very poor area of Kabul.

134 Forty-one background interviews with senior officials in the $\mathrm{MoPH}$, medical and 135 midwifery educators, programme directors, community leaders and non-Afghan

136 anthropologists and linguists provided insights into the wider health system,

137 sociocultural, political and historical context of care. Background interviews were 138 ongoing throughout and were part of the iterative process. They continued to produce 139 new perspectives and this provided a check against forming premature judgements 140 on the nature of hospital culture and life.

141 Interviews were digitally recorded if consent was given; alternatively, notes were 142 hand-written and expanded shortly afterwards. Interviews were conducted in Dari or 143 English. RA transcribed all interviews. As a quality control measure (Kirkpatrick \& van 144 Teijlingen, 2009), recorded Dari interviews were transcribed and translated by an 145 Afghan researcher. Data were analysed thematically (Braun \& Clarke, 2006). Each 146 interview was coded, then similar codes were grouped into categories (Holloway \& 147 Galvin, 2017). Categories were checked against the data, linked with other 148 categories and redefined into higher order concepts (Forrest Keenan et al., 2005). To achieve a systematic analysis that also maintained the contexts, each data set was 
analysed separately prior to analysing across the data as a whole. The data from observation, background interviews, semi-structured interviews, FGDs and from each discrete cadre formed part of the final analysis. Conflicting perspectives or opinions were included and discussed as they represent the complexity of social life and 154 interactions.

155 RA conducted the majority of the analysis, however, co-authors (EvT and KR) read and coded several interviews. During data analysis the developing themes were

157 discussed with Afghan colleagues as well as two linguists and cultural experts to 158 ensure that these resonated with wider Afghan values and culture. This was 159 important in endeavouring to produce "culturally competent health knowledge" (Tsai 160 et al., 2004). The developing analysis and concepts were also discussed with the co161 authors. This article discusses the impact of sociocultural norms and the political 162 economy on healthcare providers and the care of women in facility-based childbirth.

163 Ethical approval was granted by the MoPH Institutional Review Board and 164 Bournemouth University. Written and verbal explanations regarding the aims of the research were given to staff members prior to interview. As the researcher was a foreigner introduced by the $\mathrm{MoPH}$, it was vital to ensure that participants understood 167 that they were able to refuse an interview (Christakis, 1992; Nuffield Council on 168 Bioethics, 2002). Ongoing informed consent was obtained from each participant. In one case, an interview with a care assistant was immediately brought to a close as some discomfort was sensed. Because of Afghan politeness and her low status 171 within the hospital hierarchy it was possible that she felt unable to say no to a request 172 for an interview. After this, no formal interviews were conducted with care assistants 173 but opportunities were taken for informal conversations with others in corridors or 174 during work. This ensured that they knew their opinions were valued but gave them the power to initiate conversation or to walk away. 


\section{Findings}

177 Initial observations revealed familiar features - hospital staff in uniforms, women in

178 childbirth, busy corridors, visiting relatives, noises, smells, routine procedures and

179 morning reports. Behind the tangible, however, were other 'realities', which, in

180 addition to the 'biomedical hospital world', influenced the behaviours and priorities of

181 the healthcare providers. Social pressures and the political economy defined the

182 purpose of hospital work, controlled medical knowledge, access to care and the

183 agency of individual staff members. Furthermore, these other 'realities' elucidated

184 issues that have persistently undermined efforts to improve the quality of care.

185

186

187

188

189

190

\section{The control of knowledge}

Midwives received a competency-based education designed to enable them to manage most complications of pregnancy and childbirth. Using their new skills in the clinical areas, however, was a challenge. A junior midwife explained she had not been allowed to care for women having their first baby, perform an episiotomy or manual vacuum aspirations.

The old midwives tell us, 'this is not a midwife's job, this is doctors' work'. They say: 'Here, what midwives do is only cleaning, arranging the ward and checking the blood pressure of patients'.

One midwife complained that not only were midwives discouraged from using their skills, senior midwives deliberately undermined her confidence by suggesting she had made mistakes, and would be reported and punished.

Healthcare providers explained that if they tried to share their knowledge they faced suspicion and opposition. A resident doctor started teaching colleagues about neonatal resuscitation having recently attended a "Helping Babies Breathe" course 
200 (Arlington et al., 2017). Some residents were interested to learn, whilst others

201 ridiculed her - accusing her of wanting to 'show off', to promote herself. An

202 experienced midwife, who wanted to improve standards, was reprimanded by senior

203 midwives for training her colleagues.

204

205

206

207

'You can't train, who are you? You are a midwife not a teacher'. They don't like me to do training, she explained, because they think if I do training I will be promoted...they don't think how good it is that the knowledge of staff is becoming higher.

208 The residency programme for newly qualified doctors provided clinical training 209 designed to equip them as consultant obstetricians and gynaecologists. Each resident was assigned a trainer but many complained that unless they were related

211 to a senior doctor they were left alone to develop clinical skills, practising on women

212 in childbirth (Arnold et al., 2014). A foreign doctor with many years' experience 213 mentoring doctors in Afghanistan explained:

In teaching hospitals senior doctors are called trainers but many lack a sense of responsibility to train... some regard the resident doctors as competitors, that if you are too good at training the resident may take away your private patients.

217 With some exceptions, knowledge and skills were not considered resources to be

218 shared for the benefit of all but a resource to be controlled, kept to oneself and one's 219 family.

\section{2. Equity or patronage}

221 Increasing 'equitable access' to healthcare is a strategic priority of the MoPH

222 (Government of the Islamic Republic of Afghanistan, 2011, p.21). A woman in one 
223

224

225

226

227

228

229

230

231

232

233

234

235

236

237

238

239

240

241

242

community FGD explained, however, that when poor women came to the hospital the type and quality of care they received depended on the attitude of individual staff.

If a woman is poor and the doctor is compassionate they will help and use the hospital medicines but if the doctor is not kind but cruel, like a stone, then the woman's relative will be left at the hospital gate and the woman will be forgotten on the hospital's bed, and if something happens to her no action is taken.

Interestingly, in this quote, there is no notion of equity as a right but rather good care being dependent on the personal attributes of healthcare providers i.e. being compassionate. "If something happens..." implied that if a poor woman suffered a complication or died healthcare providers would not be held to account. A nonAfghan midwife who had experience of many Afghan maternity hospitals confirmed:

Here [in the health system] I think sadly - there's inequity, if women are poor and uneducated I think they are treated badly...

The quality of care was also dependent on family ties. If the woman in childbirth was related to or had a family connection with one of the hospital staff they would expect to receive better care than women without connections. A non-Afghan surgeon with many years in the health system explained, "the one overriding factor (in who gets good or bad care) is connections. You've got to be related or know someone". A woman in the other FGD explained:

Nobody feels responsible, so if you don't have a wāsita [an intermediary, middleman, advocate or go-between] the staff will not pay attention or care for you.

Some staff explained that they cared for women like their own family or that this work was their service to Allah. Several healthcare providers complained that if they gave 
247 extra care to a woman with complications the relatives of other women would scold

248 them vehemently, accusing them of neglecting their relative.

249 Observations revealed a broad spectrum of care practices. Staff members generally

250 worked hard, often overwhelmed by the numbers of women in childbirth. Kindness

251 and warmth between staff and women in childbirth was observed, however, most

252 women laboured alone, distressed and unsupported while at times healthcare

253 providers sat together talking.

254 The strength of Afghan kinship ties and obligations is unequivocal; the duty of care

255 towards strangers is more tenuous. The healthcare provider role requires caring for

256 non-family members. A non-Afghan nurse manager with 30 years' experience in

257 Afghanistan explained:

258

The attitude of staff is generally that the patient who is not a member of my

259 family or clan is not interesting for me. If they give me money, yes this is interesting, so I will help a bit.

261 An anthropologist, who had lived with Afghan families, explained that even in

262 families, care is connected to respect and respect is linked to your position in the

263 family hierarchy. "Status demands respect" she explained, "and respect demands

264 care". A historian and cultural expert concurred:

Respect in Afghan society is only due to equals or those above you in status. If there is no embedded cultural idea of respect for those of lower status then there is no obligation to show care. Patients by virtue of the fact that they are seeking the aid of the hospital automatically classify as below the care provider.

269 Status, related to family importance and connections, educational background, economic situation and possibly ethnicity influenced access to care and the quality of 
271 care for women in childbirth; likewise, status affected the opportunities of healthcare

272 providers. A newly qualified midwife explained the difficulties she experienced

273 securing her job in the hospital. She had to sit a MoPH exam where only the top

274 students were employed. I asked her if connections or wāsita also affected job

275 opportunities?

Researcher /first author: So does it help if you know someone in the Ministry? Midwife: Maybe... (lot of laughing from her and the interpreter) yes, it's a custom in Afghanistan!

279 The official way to secure a job was to achieve the highest result in an exam.

280 Unofficially, however, the applicant had to know someone in the ministry or hospital 281 to be employed there.

282 Resident doctors and midwives explained that the same people were often chosen to

283 attend workshops and training courses. "Here it is the special people who get sent 284 every time", a midwife complained. During observation a senior doctor became very 285 animated about the need for a fair system and career pathway for staff.

We need a system where there are fences and people are unable to step to the right or to the left but have to keep following the way step by step. We do not have such a system at present.

289 This senior and highly motivated doctor had been overlooked for promotion for many 290 years. Numerous Afghans explained that no one could hold a senior position, in a 291 hospital or government ministry, without having powerful connections. As a 292 community leader confirmed, "Political support is necessary for senior positions, not 293 just knowledge". 
294 Connections to important, powerful people were vital for everyone in this maternity

295 hospital. Without such patronage hospital staff as well as women in childbirth were

296 disadvantaged. Although there were exceptional staff members who cared for

297 everyone, the over-riding factor in receiving quality care was not need but status;

298 who one was and to whom the family were connected. Secondary to this, was the

299 ability to pay for services.

\section{3. The purpose of hospital work}

301 Many midwives and doctors talked of wanting to "serve the needs of their patients

302 well". Staff explained that they "became happy" when seriously ill women recovered

303 because of their care. Others said their own mothers encouraged them to treat the

304 'patients' well. Some doctors and midwives were endeavouring to improve standards

305 and were distressed with the deficiencies in care.

306 Women in the community, however, portrayed a maternity system that often lacked

307 basic clinical care and kindness. A young woman in the community FGD said:

There is no sympathy, or good behaviour. I delivered my first child in the hallway of the hospital. Here there is no monitoring and nobody answers your concerns... I had a very bad pain and couldn't understand anything.

311 A community leader, and a foreign doctor with many years' experience in the country,

312 concurred that throughout Afghanistan a job is considered to come with privileges,

313 including the opportunity to use a position to benefit one's family. The benefit could

314 be gifts or money given by, or requested from, women in childbirth or their families.

315 Senior positions provided the opportunity to ensure family members were awarded

316 places on training courses, promoted or appointed to jobs, even in preference to

317 more appropriately qualified applicants. The more senior the position held, the higher 
318 the family expectations and pressures. A community leader posed the question - are

319 staff working in the hospital "to serve or to be served? To serve the patients or have

320 their needs served by the patients?" He explained that because patients benefit from

321 healthcare providers' years of study, knowledge and skills, the staff expected some

322 remuneration in return. A woman in a FGD explained:

Believe me, when I went to the hospital to deliver my baby, in each step they asked for money and I had to pay them, even when I wanted to leave.

325 A foreign nurse with extensive experience in Afghanistan explained that during the 326 Soviet occupation (1979-1989) everyone was guaranteed a job. Large numbers of 327 government employees were consequently paid for attendance rather than doing 328 their job. If employees were required to do something then they would expect 329 additional payment. This, she said, was potentially connected to the expectation of 330 shīrnī. (Shīrnī, meaning 'sweets'/'sweetener', refers to the customary practice or 331 obligation to 'treat' close friends, family and colleagues to a gift or meal on, for 332 example, getting promoted, but can refer to a bribe). In addition it could partly explain 333 the unwillingness to take on extra work in an already busy hospital. A senior midwife 334 said that she tried to encourage other midwives to feel responsible for checking 335 women in childbirth to justify their salary. You have to do good work and earn your salary, she told a midwife. 'No!' The midwife said - 'I earn my salary coming to this hospital'. They have old ideas from a previous time, the senior midwife explained, but now we want to change their ideas.

Doctors and midwives represented the investment of families: fathers, brothers,

341 husbands, grandmothers or mothers who had permitted or supported their studies. In 342 this collectivist society a healthcare provider's first priority was to honour that 
343 investment and their family obligations. Some were obliged to study medicine or

344 midwifery (Arnold et al., 2014) and this may partly explain issues with motivation.

345 Economic necessity meant that supplementing salaries could represent the

346 difference between family survival and destitution. In the ongoing turbulent Afghan

347 context, the protection of family networks is also vital for survival; disloyalty to family

348 jeopardises that protection. A nurse midwife who had worked in the country for many

349 years explained:

Because there is no formal system of protection against misfortune that is why the informal power structures are so important.

352 A senior doctor explained, however, that unborn babies suffered as staff, spent time 353 generating shïrni from the relatives of women in childbirth rather than regularly 354 checking fetal hearts, a vital element of high quality intrapartum care. This confirmed 355 the observation that generally, regular checking of women in labour and fetal hearts 356 was not done and fetal hearts were only listened to following internal examinations. A 357 woman in a discussion group concurred: In Kabul's hospitals there is no system of investigation or monitoring. After first examination they leave women in hallways of the hospital and nobody will take care of them...

361 A doctor explained that taking shīrnī had become a habit for some regardless of 362 need. In addition, she alleged, there was a "hidden system" [of taking bribes]... 363 based on relationships, involving senior people. This system [of taking money] is very dangerous for this hospital. Junior staff members have a relationship with senior staff and it goes up, up, up... it is the 

to monitor women and babies].

368 Several participants indicated that powerful people from outside the hospital were 369 involved. One participant explained that an attempt to expose the practice had 370 resulted in a cover up and staff members threatened. She explained that the same 371 system existed in all Kabul maternity hospitals. Moreover, women suspected that 372 medical interventions were not always done for their benefit. This issue is everywhere...they force you to have surgery and they will open your belly. Natural birth is very low these days...they are doing surgery to receive more money or to learn on poor people how to perform surgery.

376 Several healthcare providers gave examples of the fraudulent use of clinical 377 interventions to generate additional income: it was beyond the remit of this study to 378 examine these claims. The concept of healthcare providers being there to primarily 379 serve the needs of patients, however, failed to resonate with the experiences of 380 women in the community, background interviewees or observations.

\section{Discussion}

382 This study demonstrates the depth and complexity of issues that affect the provision 383 of care in this Kabul maternity hospital. It highlights that suboptimal care cannot 384 solely be attributed to a lack of knowledge, training, evidence-based policies or procedures but is connected, in part, to the internal values and priorities of staff, the societal and institutional culture. Although healthcare providers generally look the

387 same in hospitals across the globe, this study reveals they have different ways of understanding the world. They may work in a 'caring' profession but perceive the 
390 in guarding their skills rather than sharing them. A sense of responsibility to strangers

391 might clash with kinship obligations, the institutional culture, and the wider social

392 environment. Furthermore, public health institutions may not only provide care, they

393 may also be lucrative sources of income for political elites.

394 Speakman and colleagues $(2014$, p8) claim that recent health initiatives led to a 395 "rapid acceptance of global best practices" among Afghan stakeholders in midwifery 396 education. Our findings, however, illuminate some inherent problems; whilst the 397 institutions, programmes and systems of biomedicine have been adopted, the day-to398 day functioning of the hospital reveals the persistence of divergent values and 399 competing power structures. It reveals a system of biomedicine that is contextually 400 specific having been shaped by culture, history and politics. Recent developments in 401 education, policies and programmes have increased staff expectations but also 402 frustrations at the gulf between the ideal and the constraints of their world.

403 Competing discourses can be seen in the control of knowledge. From a biomedical 404 perspective access to knowledge is important to determine best practice, hence, 405 knowledge is a resource to be shared for the benefit of all (Beauchamp \& Childress, 406 2013). In a more status-oriented society not sharing knowledge or skills is a way of 407 maintaining respect, superiority and power. The latter was highlighted by several 408 interviewees and confirmed by Foster (2009, p.37), a non-Afghan surgeon, who 409 reported that senior Afghan doctors did not entrust their knowledge to others but 410 rather accused young doctors of "stealing their skills". Traditional stories from the 411 region expound the wisdom of keeping some knowledge to oneself. The Persian poet 412 Sa 'dī Shĩrāzī (d.1292) advised his listeners "Never empower a friend so much, that if 413 he becomes your enemy, he is able to defeat you" (Loewen, 2008, p.69).

414 Furthermore, this monopoly on certain knowledge or skills (Arnold et al., 2014) may 415 be used to generate additional income in the private practice of doctors or midwives. 
416 The importance of connections and patronage in accessing healthcare has been

417 documented in low and middle-income countries (Andersen, 2004; Rivkin-Fish,

418 2005). In his anthropological examination of maternal mortality in obstetric

419 emergency services in West Africa, Jaffré (2012, p.6) explained that "globally, entry

420 into services is made through 'acquaintances'”.

421 It is not only Afghan women in childbirth who are disadvantaged if they lack a wāsita,

422 but also the midwives and doctors caring for them who may miss out on employment

423 and promotion opportunities. Ethical principles and the importance of attitudes that

424 promote equitable access are emphasised in the midwifery curriculum (Ministry of

425 Public Health, 2009). The MoPH reproductive health policy states that "poor and

426 underserved groups" are to be prioritised and inequities decreased (Ministry of Public

427 Health, 2012, p.3). Our study found, however, that inequitable access and treatment

428 was still the usual experience of women in childbirth. As an assessment of the

429 midwifery workforce reported, Afghanistan is rich in policies - the issue is

430 implementation (Jhpiego, 2013).

431 Afghanistan is not unique. Although the laws in many countries are conceived to

432 serve the ideal of equality, Hofstede et al. (2010, p.54) noted that "there are few

433 societies in which reality matches the ideal". Low, middle and high-income countries

434 still struggle to achieve equality or equity in healthcare (Barros et al., 2012; David \&

435 Collins, 2014; Mumtaz et al., 2014). Farmer (1999, p.1492) contends that: "Even as

436 our biomedical interventions become more effective, our capacity to distribute them

437 equitably is further eroded".

438 It is impossible to make generalisations on the primary focus or purpose of work for

439 the heterogeneous healthcare providers in this study. The strong connection to family

440 needs, obligations and demands, however, was evident in staff of all cadres and 
441 seniority. In their analysis of national cultural differences, Hofstede and colleagues

442 (2010, p.90) noted that globally the vast majority of people live in societies "where the

443 interest of the group prevails over the interest of the individual". Furthermore,

444 individuals in these collectivist societies grow up to think of themselves as part of a

445 'we' group (or in-group), the major source of their identity and security to which they

446 owe life-long loyalty. Minkov (2007) labelled this "exclusionism" where favours,

447 privileged treatment and sacrifices are reserved for the in-group, while others, (the

448 out-group) may be treated with indifference, rudeness and hostility.

449 Values are acquired through socialisation and although the more superficial facets of

450 a culture may change, values are the most stable element (Hofstede et al., 2010).

451 Although Afghan doctors and midwives are taught the principles of equity, these

452 might not resonate with their experiences or the values of their society. Moreover,

453 adopting these principles at work might place them in opposition to colleagues, the

454 prevailing institutional culture and the powerful elite. The importance of adhering to

455 social expectations in Afghan society was demonstrated by Eggerman and Panter-

456 Brick (2010) who conducted 2022 interviews with Afghan children age 11-15 and

457 their adult caregivers. Cultural values such as service to family were found to be the

458 bedrock of resilience, that underpinned self-respect and dignity, providing hope in a

459 violent, war-affected setting (Eggerman \& Panter-Brick, 2010). The authors found,

460 however, that cultural dictates and social expectations also created a sense of

461 entrapment where personal aspirations had to be sacrificed and failure resulted in

462 psychosocial distress. Similarly, midwives, care assistants and doctors in our study

463 were frustrated by the injustices they experienced because of the pervasive nepotism

464 and their own powerlessness within the system. They were also distressed that

465 women in childbirth were deprived of the care they needed. Healthcare providers

466 were aware that public health institutions should provide care for all, however it 
appeared that more compelling needs and demands usually surpassed the needs of

468 poor, uneducated, unconnected women. Interestingly, the assumption of relatives

469 that if a woman was receiving extra care it was because of connections not clinical

470 need further highlights how patronage is ingrained in Afghan society.

471 Jaffré $(2012$, p.6) also concluded that "the medical organisation is permanently

472 duplicated by an interconnected system". "It is the same everywhere" he states, "the

473 behaviours of health personnel always mix technical norms with habits and local

474 customs" (p.8). A notable difference in our study was that the 'interconnected system'

475 was complicated by economic hardship, the legacy of over three decades of conflict,

476 ongoing instability, and pressure from powerful people inside and outside the

477 hospital.

478 Service users in multiple studies have confirmed the need for out-of-pocket

479 expenditure in Kabul hospitals (Howard et al., 2014; Rahmani \& Brekke, 2013). The

480 Afghanistan Reproductive Age Mortality Survey (Bartlett et al., 2017) reported that

481 the cost of delivery care, especially in government hospitals (which should be free) is

482 concerning. Our study suggests that these findings represent more than individual

483 staff supplementing their income. In 2016 health and education services in three

484 Afghan provinces were examined in an attempt to understand why qualitative

485 improvements have been so much more difficult to achieve than quantitative ones

486 (Afghanistan Research and Evaluation Unit, 2016). The roles of government officials,

487 local elites, armed opposition and the effect of political settlements in each province

488 were examined. It was concluded that political settlements have a major impact on

489 service delivery. Furthermore, 'strongmen' linked to the ruling elites in Kabul could

490 have serious impacts on service delivery and quality, "because of their attempts to

491 exploit them [hospitals and schools] as a source of patronage and revenue"

492 (Afghanistan Research and Evaluation Unit, 2016, p.3). A report commissioned by 
493 the Minister of Public Health detailed the magnitude of corruption within the health

494 system (Independent Joint Anti-Corruption Monitoring and Evaluation Committee,

495 2016). This gives support to the claim of a study participant, that income generation

496 in public maternity hospitals was not confined to 'poor individual staff' but included an

497 efficient system involving senior figures.

498 The dominance of patronage networks in Kabul's public maternity hospitals reflects

499 the persistence of patronage networks at all levels of Afghan society (Sharan, 2011).

500 In addition, Schmeidl (2016) contends that because the international community

501 failed to adapt the process of democracy to the local, social and historical context

502 state-building has been undermined, and neo-patrimonialism has flourished.

503 Although current literature acknowledges that social-cultural barriers can affect the

504 quality of care, the danger is that the view of those barriers can be limited and

505 western centric focusing on traditional practices, gender and the status of women in

506 societies (Filby et al., 2016). While our study acknowledges these issues, it contends

507 that there are deeper layers of culture and meaning that offer more substantial

508 insights into the reasons that inputs, (such as the education of healthcare providers

509 and the presence of evidence-based policies and strategies), fail to produce the

510 desired outputs.

511 The findings suggest that social expectations and political pressures influenced

512 decision-making and the quality of care as Afghan healthcare providers were

513 confronted daily with the clash between world-views and values. One world-view

514 focused on the woman in childbirth and what was best for her as identified by

515 scientific research. Another world-view focused on personal survival, living life

516 according to the dictates of society and family, the deeply held 'inviolable norms' 
517 (Weber, 1946, p.296) and negotiating the highly politicised work environment. These

518 competing discourses or 'parallel worlds' constantly undermined the quality of care.

519 From a global perspective one can see that foreign aid brings with it the need to

520 produce fast results to satisfy international donors and governments (Zürcher, 2012).

521 The pressure for results, however, can leave no time to explore underlying

522 constraints and the values that control behaviour in the workplace. There are also

523 often inherent assumptions in international development strategies regarding the (a)

524 motivation and agency of individual healthcare providers; and (b) all health systems

525 having the same common foundation of biomedical principles and ethics (Deb Roy,

526 2018; Mumtaz et al., 2015).

527 For the outsider, working alongside Afghan colleagues, the intangible world that

528 profoundly affects every facet of hospital life might be completely unknown. For the

529 Afghan this world is so known it is unremarkable. Barfield (2010, pp.31-32), using the

530 concept of 'habitus' (Bourdieu, 1977) explains that for Afghans the "material

531 habitus... is so taken for granted that it is invisible, even when of critical importance".

532 Our findings suggest, as do those of Wood (2000, p.226) that we cannot understand

533 the way people work, their motivations and priorities or, therefore, make

534 improvements "without calculating for the overriding context".

535 Currently the MoPH with international partners are endeavouring to improve the 536 quality of maternity care through a Helping Mothers and Children Thrive (HEMAYAT)

537 project including Respectful Maternity Care (RMC) initiatives (Jhpiego, 2018;

538 Pajhwok, 2016). Our findings suggest that, in addition, the conflicting discourses and

539 political pressures on staff at all levels in Afghan public health and government

540 institutions need to be acknowledged. Moreover, it is Afghan insider cultural 
541 knowledge, ingenuity and courage that are vital to address these powerful worlds that

542 presently undermine high quality respectful care.

543 As Panter-Brick and Eggerman pointed out (2018, p.234) "an even handed view of

544 medical systems is one that understands why diverse ways of framing healer-patient

545 relationships co-exist and how this is related to historical, social and political

546 contexts". It is critically important for stakeholders to understand that diverse,

547 conflicting ideologies and political economies may have a profound impact on

548 healthcare institutions, the people who work there and consequently on standards of

549 care. Unless we examine the social and political context in which healthcare is

550 delivered we are deemed to stay "conflict-blind" (Afghanistan Research and

551 Evaluation Unit, 2016, p.6) and solely focus on technical explanation and solutions

552 for the persistence of low quality services.

\section{Strengths \& limitations of the study}

554 Conducting cross-cultural research as a non-Afghan western woman presented a

555 myriad of inherent pitfalls. It was vital that every decision from study design to

556 fieldwork and analysis was accompanied by reflexivity regarding the researcher's

557 own socio-historical perspectives, underlying judgements and assumptions. Afghan

558 associates, cultural and linguistic experts were vital sounding boards throughout the

559 research process. They helped to refine the study design, clarified misconceptions

560 and provided deeper cultural insights. It was also important to consider the impact of

561 a foreigner's presence on staff members' behaviours during observation, and how to

562 establish a common humanity with the complex individuals behind the polite

563 exteriors. Another limitation was the use of an interpreter as her social status, age,

564 gender, interpersonal communication and language skills inevitably had an impact on

565 the data. Every effort was made to orientate, support and facilitate her with the 
interpretation process. It is inevitable, however, that some cultural nuances and

567 richness will have been missed.

568 Although the quality of care in facility-based childbirth is currently receiving significant

569 attention this study presents a more unusual perspective. It examined care and the

570 caregivers in particular through a constructionist approach that encompassed not

571 only the biomedical and clinical but also the broader social context. It explored the

572 way that society, history and politics have shaped and continue to shape healthcare

573 provision in a uniquely Afghan manner.

574 As each cultural setting is unique the specific findings from this study cannot be

575 generalised. This research has relevance in many settings, however, as it

576 demonstrates the potential of inductive qualitative studies to look beyond technical

577 explanations and solutions for poor quality care. It reveals that understanding the

578 context of healthcare is pivotal to understanding behaviour; it challenges

579 conventional assumptions about individual staff agency and common strategies to

580 improve the quality of care.

581 Another strength of this study was the multiple methods that helped crosscheck the

582 findings. In addition, obtaining information from diverse groups of people provided

583 rich insights of Afghan society and the multiple interrelated issues that profoundly

584 undermined healthcare provision.

\section{CONCLUSION}

586 At the heart of biomedical principles is the woman in childbirth and what is best for

587 her according to scientific research (van Teijlingen, 2005). Survival strategies in a

588 still volatile insecure setting like Afghanistan depend on allegiance to family and

589 cultural dictates, and this translates into the working environment. This research 
revealed a direct link between the values and social obligations of Afghan healthcare

591 providers, the political economy, and the quality of care. Diverse, conflicting world-

592 views defined the experiences of both women in childbirth and the staff who cared for

593 them. Equity of access and evidence-based practice were generally eclipsed by more

594 powerful values and obligations. Some staff worked with passion and strove for

595 equity. They appeared better motivated and able to balance the conflicting demands

596 but generally they faced hostility and opposition, even from the relatives of women in

597 childbirth.

598 Clashes between values in healthcare settings can be found in low, middle and high599 income countries. To assume that equity of access and knowledge for the benefit of

600 all is a universally accepted value in healthcare ignores the complexity of human

601 societies. This research suggests that the primary allegiance of healthcare providers

602 will be to the values of their society and to personal survival. Ignoring the impact of

603 social and political pressures on healthcare provision undermines the possibility for

604 designing effective interventions. Furthermore, it can result in complicity in the

605 ongoing neglect or mistreatment of the most vulnerable.

606 In the Afghan context there are questions for civil society, the Ministry of Public

607 Health, government and international stakeholders about the value of women's lives

608 and the parallel worlds that undermine Afghan maternity services. Further research is

609 needed into the good practice displayed by some staff to understand why they are

610 different and if this could be a starting point for change in others. More research is

611 required into the parallel worlds of health managers; the social and political pressures

612 that effect policy implementation. At grass roots level, action research could be used

613 to implement promising ideas from staff at every level as micro-actions of change. 
614 Local solutions and courageous leadership are required to improve the quality of care

615 in maternity hospitals and address these challenging issues. Ultimately initiatives

616 must be based on Afghan culture and ingenuity in grappling with divergent values

617 and providing support to healthcare providers.

618 More generally, our findings suggest that aspirations of quality, equity and respectful

619 care for women in childbirth need to be tempered with a major paradigm shift by

620 donors and the global health community. It is not sufficient to see healthcare though

621 a one-dimensional biomedical lens. Healthcare is value-laden. Achieving quality and

622 equity requires not only technical know-how, policies and an enabling environment, it

623 also requires the adoption of the underpinning values that may be at variance with

624 the prevailing societal norms and political pressures, even in high-income countries.

625 The next level of quality improvement in maternity services, therefore, requires

626 digging deep (Panter-Brick \& Eggerman, 2018) with 'insiders' to expose the multiple

627 worlds that undermine quality. This must be followed by international support for

628 context specific ways forward.

629

630

631

632

633

634

635

636

637

638

639

640

641

642

643

644

645

646

647

648
Afghanistan Research and Evaluation Unit. (2016). The Political Economy of Education and Health Service Delivery in Afghanistan. Issues Paper. Kabul: Afghanistan Research and Evaluation Unit http://www.areu.org.af.

Akseer, N., Salehi, A.S., Hossain, S.M., Mashal, M.T., Rasooly, M.H., Bhatti, Z., et al. (2016). Achieving maternal and child health gains in Afghanistan: a Countdown to 2015 country case study. Lancet Glob Health, 4, e395-413.

Andersen, H.M. (2004). "Villagers": Differential treatment in a Ghanaian hospital. Soc. Sci. Med., 59, 2003-2012.

Arlington, L., Kairuki, A.K., Isangula, K.G., Meda, R.A., Thomas, E., Temu, A., et al. (2017). Implementation of "Helping Babies Breathe": A 3-Year Experience in Tanzania. Peds., 139.

Arnold, R., van Teijlingen, E., Ryan, K., \& Holloway, I. (2014). Understanding Afghan healthcare providers: a qualitative study of the culture of care in a Kabul maternity hospital. BJOG, 122, 260-267.

Barfield, T.J. (2010). Afghanistan: a cultural and political history. Princeton: Princeton University Press.

Barros, A.J., Ronsmans, C., Axelson, H., Loaiza, E., Bertoldi, A.D., Franca, G.V., et al. (2012). Equity in maternal, newborn, and child health interventions in Countdown to 2015: a retrospective review of survey data from 54 countries. Lancet, 379, 1225-1233. 
Bartlett, L., LeFevre, A., Zimmerman, L., Saeedzai, S.A., Torkamani, S., Zabih, W., et al. (2017). Progress and inequities in maternal mortality in Afghanistan (RAMOS-II): a retrospective observational study. Lancet Glob Health, 5, e545e555.

Beauchamp, T.L., \& Childress, J.F. (2013). Principles of biomedical ethics. 7th edition, New York: Oxford Universty Press.

Bourdieu, P. (1977). Outline of a theory of practice. Cambridge: Cambridge University Press.

Braun, V., \& Clarke, V. (2006). Using thematic analysis in psychology. Qual. Res. Psychol., 3, 77-101.

Brewer, J.D. (2000). Ethnography. Buckingham: Open University Press.

Central Statistics Organisation, Ministry of Public Health, \& and ICF International. (2016). Afghanistan Demographic and Health Survey 2015: Key Indicators. Kabul, Afghanistan and Rockville, Maryland USA.: Central Statistics Organisation, Ministry of Public Health, and ICF International.

Christakis, N.A. (1992). Ethics are local: engaging cross-cultural variation in the ethics for clinical research. Soc. Sci. Med., 35, 1079-1091.

Currie, S., Azfar, P., \& Fowler, R.C. (2007). A bold new beginning for midwifery in Afghanistan. Midwifery, 23, 226-234.

David, R.J., \& Collins, J.W. (2014). Layers of inequality: power, policy, and health. Am J Public Health, 104 Suppl 1, S8-S10.

Deb Roy, R., 12/4/2018. Decolonise science - time to end another imperial era. The Conversation Available from: https://theconversation.com/decolonisescience-time-to-end-another-imperial-era-89189 [Accessed: 12/4/2018].

Eggerman, M., \& Panter-Brick, C. (2010). Suffering, hope, and entrapment: Resilience and cultural values in Afghanistan. Soc. Sci. Med., 71, 71-83.

Farmer, P. (1999). Pathologies of power: rethinking health and human rights. Am J Public Health, 89, 1486-1496.

Filby, A., McConville, F., \& Portela, A. (2016). What Prevents Quality Midwifery Care? A Systematic Mapping of Barriers in Low and Middle Income Countries from the Provider Perspective. PLoS One, 11, e0153391-e0153391.

Forrest Keenan, K., van Teijlingen, E., \& Pitchforth, E. (2005). The analysis of qualitative research data in family planning and reproductive health care. $J$. Fam. Plann. Reprod. Health Care, 31, 40-43.

Foster, K. (2009). The role of professional knowledge in Afghan surgical training. Unpublished: University of Toronto.

Government of the Islamic Republic of Afghanistan. (2011). Strategic plan for the Ministry of Public Health (2011-2015). Kabul.

Graham, W., Woodd, S., Byass, P., Filippi, V., Gon, G., Virgo, S., et al. (2016). Diversity and divergence: the dynamic burden of poor maternal health. Lancet, $388,2164-2175$.

Green, J., \& Thorogood, N. (2018). Qualitative methods for health research. 4th edition, Thousand Oaks: SAGE Publications Ltd.

Gregorian, V. (1969). The Emergence of Modern Afghanistan: The Politics of Reform and Modernization, 1880-1946. Stanford: Stanford University Press.

Guidotti, R.J., Kandasamy, T., Betran, A.P., Merialdi, M., Hakimi, F., Van Look, P., et al. (2009). Monitoring perinatal outcomes in hospitals in Kabul, Afghanistan: The first step of a quality assurance process. J. Matern. Fetal. Neonatal. Med., 22, 285-292.

Hammersley, M., \& Atkinson, P. (2007). Ethnography: principles in practice. 3rd edition, London: Routledge. 
Hofstede, G., Hofstede, G.J., \& Minkov, M. (2010). Cultures and Organisations: Softwear of the Mind - Intercultural Cooperation and its Importance for Survival. 3rd edition, New York: McGraw-Hill.

Holloway, I., \& Galvin, K. (2017). Qualitative research in nursing and healthcare. [electronic resource]. 4th edition, Chichester, UK: Wiley \& Sons, Ltd.

Howard, N., Woodward, A., Patel, D., Shafi, A., Oddy, L., Veen, A., et al. (2014). Perspectives on reproductive healthcare delivered through a basic package of health services in Afghanistan: a qualitative study. BMC Health Serv. Res., 14, 359.

Hunte, P.A. (1980). The Sociocultural Context of Perinatality in Afghanistan. Unpublished: The University of Wisconsin-Madison.

ICM. (2002). Essential competencies for basic midwifery practice. The Hague: ICM. Independent Joint Anti-Corruption Monitoring and Evaluation Committee. (2016). Vulnerability to Corruption Assessment in the Afghan Ministry of Public Health. Kabul, Afghanistan.

Jaffré, Y. (2012). Towards an anthropology of public health priorities: maternal mortality in four obstetric emergency services in West Africa. SA/AS, 20, 3-18.

Jhpiego. (2013). Afghanistan's Midwifery Workforce Assessment: Rapid assessment in priority areas. Kabul: Jhpiego and USAID.

Jhpiego. Jhpiego Afghanistan. Where we work Available from: https://www.jhpiego.org/where-we-work/afghanistan/ [Accessed: 17/04/2018].

Kim, Y.-M., Tappis, H., Zainullah, P., Nasrat, A., Evans, C., Bartlett, L., et al. (2012). Quality of caesarean delivery services and documentation in first-line referral facilities in Afghanistan: a chart review. BMC Pregnancy Childb., 12.

Kirkpatrick, P., \& van Teijlingen, E. (2009). Lost in Translation: Reflecting on a Model to Reduce Translation and Interpretation Bias. Open Nurs. J., 25-32.

Koblinsky, M., Moyer, C.A., Calvert, C., Campbell, J., Campbell, O.M., Feigl, A.B., et al. (2016). Quality maternity care for every woman, everywhere: a call to action. Lancet, 388, 2307-2320.

Loewen, A. (2008). New Horizons for Afghanistan - Principles of Leadership Development. Kabul: Operation Mercy.

Ministry of Public Health. (2005). National Health Policy 2005-2009 and National Health Strategy 2005-2006. A policy and strategy to accelerate implementation. Kabul: Ministry of Public Health.

Ministry of Public Health (2009). Curriculum for Community Midwifery Education. 3rd edition, Kabul: Ministry of Public Health.

Ministry of Public Health. (2012). National Reproductive Health Policy 2012-2016. In Reproductive Health Task Force (Ed.). Kabul: Ministry of Public Health.

Ministry of Public Health. Improvements in key health indicators sets new benchmark in spite of serious insecurity. Available from: http://moph.gov.af/en/page/sehat-program [Accessed: 23/09/2017].

Minkov, M. (2007). What Makes Us Different and Similar: A New Interpretation of the World Values Survey and Other Cross-Cultural Data. Sofia, Bulgaria: Klasika i Stil.

Mumtaz, Z., Levay, A., Bhatti, A., \& Salway, S. (2015). Good on paper: the gap between programme theory and real-world context in Pakistan's Community Midwife programme. BJOG, 122, 249-258.

Mumtaz, Z., Salway, S., Bhatti, A., \& Mclntyre, L. (2014). Addressing invisibility, inferiority, and powerlessness to achieve gains in maternal health for ultrapoor women. Lancet, 383, 1095-1097.

Nuffield Council on Bioethics. (2002). The ethics of research related to healthcare in developing countries. London: Nuffield Council on Bioethics. 
Pajhwok. 21/4/2018. MoPH holds workshop to promote RMC approaches. Pajhwok Afghan News Available from: https://www.pajhwok.com/en/2016/04/12/ministry-public-health-holdsrespectful-maternity-care-workshop [Accessed: 21/4/2018].

Panter-Brick, C., \& Eggerman, M. (2018). The field of medical anthropology in Social Science \& Medicine. Soc. Sci. Med., 196, 233-239.

Pitchforth, E., Lilford, R.J., Kebede, Y., Asres, G., Stanford, C., \& Frost, J. (2010). Assessing and understanding quality of care in a labour ward: a pilot study combining clinical and social science perspectives in Gondar, Ethiopia. Soc. Sci. Med., 71, 1739-1748.

Rahmani, Z., \& Brekke, M. (2013). Antenatal and obstetric care in Afghanistan - a qualitative study among health care receivers and health care providers. BMC Health Serv. Res., 13, 166-166.

Renfrew, M.J., McFadden, A., Bastos, M.H., Campbell, J., Channon, A.A., Cheung, N.F., et al. (2014). Midwifery and quality care: findings from a new evidenceinformed framework for maternal and newborn care. Lancet, 384, 1129-1145.

Rivkin-Fish, M. (2005). Bribes, gifts and unofficial payments: rethinking corruption in post-soviet Russian health care. In D. Haller, \& C. Shore (Eds.), Corruption: Anthropological Perspectives. London: Pluto Press.

Schmeidl, S. (2016). The contradictions of democracy in Afghanistan: elites, elections and 'people's rule' post-2001. CSD, 16:6, 575-594.

Sharan, T. (2011). The Dynamics of Elite Networks and Patron-Client Relations in Afghanistan. Eur.-Asia Stud., 63, 1109-1127.

Sharkey, S., \& Larsen, J.A. (2005). Ethnographic exploration: participation and meaning in everyday life. In I. Holloway (Ed.), Qualitative Research in Health Care (pp. 168-190). Maidenhead: Open University Press.

Shaw, D., Guise, J.M., Shah, N., Gemzell-Danielsson, K., Joseph, K.S., Levy, B., et al. (2016). Drivers of maternity care in high-income countries: can health systems support woman-centred care? Lancet, 388, 2282-2295.

Sherman Heyl, B. (2001). Ethnographic interviewing. In P. Atkinson, A. Coffey, S. Delamont, J. Lofland, \& L. Lofland (Eds.), Handbook of Ethnography (pp. 369383). London: SAGE.

Speakman, E.M., Shafi, A., Sondorp, E., Atta, N., \& Howard, N. (2014). Development of the community midwifery education initiative and its influence on women's health and empowerment in Afghanistan: a case study. BMC Women's Health, 14.

Tappis, H., Koblinsky, M., Winch, P.J., Turkmani, S., \& Bartlett, L. (2016). Context matters: Successes and challenges of intrapartum care scale-up in four districts of Afghanistan. Glob. Public Health, 11, 387-406.

Temple, B., \& Young, A. (2004). Qualitative Research and Translation Dilemmas. Qual. Res., 4, 161-178.

Thomas, J. (1993). Doing Critical Ethnography. London: SAGE.

Tsai, J.H.-C., Choe, J.H., Lim, J.M.C., Acorda, E., Chan, N.L., Taylor, V.M., et al. (2004). Developing culturally competent health knowledge: Issues of data analysis of cross-cultural, cross-language qualitative research. Int. J. Qual. Methods, 3, 1-14.

United Nations Population Fund. (2014). State of Afghanistan's Midwifery 2014. Kabul: United Nations Population Fund.

van Teijlingen, E. (2005). A Critical Analysis of the Medical Model As Used in the Study of Pregnancy and Childbirth. Sociol. Res. Online, 10.

van Teijlingen, E., \& Pitchforth, E. (2006). Focus group research in family planning and reproductive health care. J. Fam. Plann. Reprod. Health Care, 32, 30-32. 
804 Victora, C.G., Requejo, J.H., Barros, A.J.D., Berman, P., Bhutta, Z., Boerma, T., et al. (2016). Countdown to 2015: a decade of tracking progress for maternal, newborn, and child survival. Lancet, 387, 2049-2059.

807 Wallace, S. (2005). Observing method: recognizing the significance of belief,

808 discipline, position and documentation in observational studies. In I. Holloway (Ed.), Qualitative Research in Health Care (pp. 71-86). Maidenhead: Open University Press.

Weber, M. (1946). From Max Weber: Essays in Sociology. New York: Oxford University Press.

Wood, G. (2000). Prisoners and escapees: improving the institutional responsibility square in Bangladesh. Public Adm. Dev., 20, 221-237.

Zürcher, C. (2012). Conflict, state fragility and aid effectiveness: insights from Afghanistan. CSD, 12, 461-480. 